\title{
Long-Term Outcomes of Occipital Nerve Stimulation for New Daily Persistent Headache With Migrainous Features
}

\section{Susie Lagrata, MSc ${ }^{1}$; Sanjay Cheema, MBBS, MRCP'; Laurence Watkins, PhD $^{2}$; Manjit Matharu, PhD $^{1} \odot$}

\begin{abstract}
Objectives: New daily persistent headache (NDPH) is a subset of chronic headache where the pain is continuous from onset. Phenotypically it has chronic migraine or chronic tension type features. NDPH is considered to be highly refractory. Occipital nerve stimulation (ONS) has been used for treatment of refractory chronic migraine but there are no specific reports of its use for NDPH with migrainous features.

Materials and Methods: Nine patients with NDPH with migrainous features were identified as having had ONS implants between 2007 and 2014 in a specialist unit with experience of using ONS in chronic migraine. Moderate to severe headache days were compared at baseline and follow-up. A positive response was defined as at least $30 \%$ reduction in monthly moderate to severe headache days.

Results: Patients had suffered NDPH for a median of 8 years (range 3-16 years) and had failed a median of 11 previous treatments (range 8-15). After a median follow-up of 53 months (range 27-108 months), only a single patient showed a positive response to ONS. At no point did the cohort as a whole show any change in monthly moderate to severe headache days or disability scores.

Conclusion: Our experience suggests that ONS is not effective in the treatment of NDPH with migrainous features even in centers with experience in treating chronic migraine with ONS. The difference in response rates of chronic migraine and NDPH with migrainous features supports the concept of a different pathophysiology to the two conditions.
\end{abstract}

Keywords: Chronic headache, chronic migraine, new daily persistent headache, occipital nerve stimulation

Conflict of Interest: Laurence Watkins has served on advisory boards for St Jude Medical and Medtronic. Susie Lagrata and Sanjay Cheema have no competing interests. Manjit Matharu serves on the advisory board for Allergan, Novartis, Lilly, and Medtronic and has received payment for the development of educational presentations from Allergan, Abbott, Medtronic, and electroCore.

\section{INTRODUCTION}

New daily persistent headache (NDPH) is a headache characterized by the acute onset of head pain that occurs daily from onset and which presents in patients without an increasing frequency of pre-existing headaches. It was first described by Vanast in 1986 as a chronic benign headache with clinical features similar to chronic tension headache where most patients would recover spontaneously within six months (1). Since this original description, multiple reports have described large cohorts of NDPH patients with migrainous features. This has led the International Classification of Headache Disorders version 3(ICHD 3) listing $\mathrm{NDPH}$ as a persistent headache, daily from onset which may be migraine-like, tension-type-like, or have features of both (2). Similarly, subsequent to the original description as a transient condition, multiple case series have recognized NDPH as a prolonged and treatment-resistant headache, especially in those with the migrainous phenotype (3-6).

Occipital nerve stimulation (ONS) is a form of peripheral nerve stimulation targeted at the occipital nerves (predominantly the greater occipital nerve) and involves the implantation of suboccipital electrodes attached to an implantable pulse generator (IPG). The procedure is performed for the preventative treatment of refractory primary headaches such as chronic migraine

Address correspondence to: Manjit Matharu, PhD, Headache and Facial Pain Group, University College London (UCL) Queen Square Institute of Neurology and The National Hospital for Neurology and Neurosurgery, Queen Square, London WC1N 3BG, UK. Email: m.matharu@uclmail.net

${ }^{1}$ Headache and Facial Pain Group, UCL Queen Square Institute of Neurology and The National Hospital for Neurology and Neurosurgery, London, UK; and 2 Department of Neurosurgery, UCL Queen Square Institute of Neurology and The National Hospital for Neurology and Neurosurgery, London, UK

For more information on author guidelines, an explanation of our peer review process, and conflict of interest informed consent policies, please go to http:// www.wiley.com/WileyCDA/Section/id-301854.html

Source(s) of financial support: There was no funding or financial support for this study.

This is an open access article under the terms of the Creative Commons Attribution-NonCommercial-NoDerivs License, which permits use and distribution in any medium, provided the original work is properly cited, the use is non-commercial and no modifications or adaptations are made. 
and chronic cluster headache. There is currently only a limited amount of controlled evidence to support the use of ONS in refractory chronic migraine although case series and systemic reviews report more promising results (7-11). Our specialist headache unit has previously reported a series of 53 patients with refractory chronic migraine with an average response rate of $45.3 \%$ at final follow-up (12). Despite the use of ONS for refractory chronic migraine, there are no specific reports in any of the above publications for the use of ONS in NDPH. This cohort therefore presents the long-term follow-up of nine patients with NDPH with migrainous features with ONS implants.

\section{MATERIALS AND METHODS}

\section{Patients}

All patients were treated by a single specialist team at the National Hospital for Neurology and Neurosurgery, Queen Square, London, UK. Implants took place between May 2007 and February 2014. Patients fulfilled the ICHD 3 diagnostic criteria for NDPH with migraine features (Box 1) (2). As intractability is not defined for NDPH, the recommendations of Goadsby et al. for the definition of intractable chronic migraine were applied (13).

Patients had been offered ONS as part of standard care for their refractory headache under the National Health Service (NHS). The treatment was carried out under the supervision of our hospital's Clinical Effectiveness Supervisory Group (CESG) and ethics approval for data collection and publication was granted by Northwick Park Hospital Research Ethics Committee, Hampstead, London, UK.

\section{Surgical Procedure}

All patients were implanted with bilateral suboccipital leads connected to an IPG. Seven patients were implanted with a Medtronic and two with Abbott (previously St Jude Medical) systems. Octad electrodes were implanted in all.

During surgery, patients were placed into the lateral position and a midline posterior cervical incision made. In earlier cases, the insertion point of the leads was the spinous process of $\mathrm{C} 1$,

Box 1. International Classification of Headache Disorders Version 3 Definition of New Daily Persistent Headache.

\section{ICHD-3: New Daily Persistent Headache}

Distinct and clearly remembered onset, with pain becoming continuous and unremitting within 24 hours

Present for $>3$ months

$\mathrm{NDPH}$ may have features of either

1. Migraine

- Headache lasting 4-72 hours,

- Headache having at least two of the following four characteristics: unilateral location, pulsing quality, moderate to severe intensity, aggravation by routine physical activity

- During headache presence of at least one of following: nausea and/or vomiting, photophobia, and phonophobia

2. Tension-type headache

- Headache lasting from 30 minutes to seven days

- Headache having at least two of the four characteristics: bilateral location, pressing/tightening/nonpulsatile quality, mildmoderate intensity, not aggravated by routine physical activity

- Both of the following: no nausea or vomiting, only one of photophobia or phonophobia passing laterally and superiorly, with the procedure conducted using a curved Tuohy needle and an image intensifier. In later cases, the implant level was superior to the nuchal line. In these cases, the lead was passed using a blunt plastic tube to reduce the likelihood of the tip of the lead being tunneled too close to the skin causing erosions. Changes in operative procedure were to reduce adverse events such as unwanted recruitment of neck muscles or erosion of the tip of the lead through the skin. Given that both techniques target the same nerve the implant technique alone would not account for any change in clinical response. Leads were anchored to cervical fascia and then tunneled to a lateral cervical or infraclavicular skin crease intermediate incision. An infraclavicular incision was made forming a pocket for the IPG, to which the distal end of the leads were attached. Silicone sheaths were used to protect lead connections. Topical gentamicin was introduced around the pocket and the incisions closed.

Trial stimulation was not conducted as our unit feels that current evidence does not yet support that the benefit of significantly improved response rates is outweighed by the risks of multiple surgical interventions.

Frequency was initially set at $70 \mathrm{~Hz}$ with a pulse width of $450 \mu \mathrm{s}$. During follow-up, the polarity of the electrodes was adjusted to achieve bilateral paresthesia in the greater occipital region. Stimulation settings were recorded at each follow-up. Medications were changed as needed at the discretion of the treating physicians.

\section{Data Collection}

All data were collected prospectively and entered onto a clinical database (Microsoft Excel, Microsoft Corporation, Redmond, WA, USA). For the first-year, postimplant patients were seen in clinic every three months and after that every 6-12 months. Data were collected on patient demographics and medication history at time of implant. Throughout follow-up data were collected on moderate to severe headache days, daily pain score and duration, headache disability scores and quality of life scores, acute and preventative medication use, ONS settings, and adverse events.

Headache disability scores included the Migraine Disability Assessment Scores (MIDAS) and Headache Impact Test- 6 Scores (HIT-6). These were recorded pre- and postimplant. Quality of life scores used were the Euro-Qol (Euro-QoL 5D index [EQ-5D] and Euro-QoL visual analogue score [EQ-VAS]), Short Form 36 Questionnaires (SF36) both physical (SF36-P) and mental (SF36-M) components, Beck Depression Inventory II (BDI-II), and Hospital Anxiety and Depression Scores (HAD-A and HAD-D). All scores were recorded before and after implant.

Adverse events were recorded as they occurred and categorized as either hardware, biological, or stimulation related. Hardware-related events were recorded if problems occurred involving the device components, biological events if reactions occurred to the device or related to the surgical procedure and stimulation related events recorded if problems were due to stimulation issues (i.e., painful stimulation) (11).

Primary outcome measure was the improvement in mean monthly moderate to severe headache days at final follow-up compared to baseline. A reduction of $30 \%$ or more was defined as a positive clinical response. This response rate was chosen inline with our previous paper on ONS in chronic migraine to allow meaningful comparison and as per the International Headache Society clinical trials subcommittee $(12,14)$. Secondary outcome 
measures were changes in median daily pain intensity, median daily headache hours, and changes in disability and quality of life scores at final follow-up.

\section{Statistical Analysis}

SPSS 24.0 statistical software was used to analyze data. Continuous variables were expressed as median plus range and/or interquartile range (IQR). Categorical variables were summarized as percentages. Median values pre- and postimplant were compared using Wilcoxon signed rank tests. All tests were two-sided with a significance level of $95 \%$.

\section{RESULTS}

\section{Demographic Data}

Between May 2007 and February 2014, nine patients with NDPH with migrainous features underwent ONS implants. Their demographic data are shown in Table 1. Median age at implant was 42.00 years (range 29-64, IQR 22.00) and four patients were female. The cohort had failed to respond to a median of 11 preventative medications prior to their implant (10-13, IQR 3.00) (Table 2). Two patients reported a previous positive response to a greater occipital nerve block (a more than 50\% reduction in headache severity or frequency lasting at least two weeks).

Patient 9 had coexistent chronic cluster headache and NDPH with migraine features but as they were able to differentiate between their two headache types they kept separate diaries to allow us to monitor the response of each phenotype throughout the follow-up.

Patient 9 and patient 3 met the ICHD-3 criteria for the overuse of acute medication prior to implant. Patient 9 was using daily triptans for their coexistent cluster headache and so these could not be stopped. Patient 3 was using daily opiates but had undergone a supervised withdrawal prior to the ONS but failed to show any significant improvement when off of the opiates. This observation excludes medication overuse headache as a cause of symptoms and therefore the patient chose to continue on the painkillers.

\section{Clinical Outcomes}

Median follow-up time was 53.00 months (27-108 months, IQR 36.50). At final follow-up, there was zero change in the monthly moderate to severe headache days of the cohort ( $p=0.414$; Table 3). No significant change was seen in the median monthly moderate to severe headache days of the cohort at any time during the follow-up: three-month median change $=0, p=0.285$; sixmonth median change $=0, p=0.655$; nine-month median change $=0, p=0.144 ; 12$-month median change $=0, p=0.285$; 24-month median change $=0, p=0.144 ; 36$-month $(n=7)$ median change $=0, p=0.180$.

A statistically significant reduction was seen across the cohort in median daily pain intensity $(-1.00$ points on verbal rating scale [VRS], $p=0.011$ ); however, this reduction is below the two-point reduction in VRS usually considered clinically significant. There was no significant change seen in median total headache days (median change $=0, p=1.00$ ) or median daily pain duration (median change $=-5.00, p=1.00$ ) (Table 3 ). There was no significant change seen in the headache disability scores (MIDAS median change $=-5.00, p=0.674$ and HIT- 6 median change $=1$, $p=0.446$ ) and the only quality of life score to show any significant change was BDI-II with a median reduction of 3.00 points $(p=0.008)$ (Table 4).

A clinically significant reduction in moderate to severe headache days was seen in only one patient (patient 5). A positive response was observed within three months of implant and was maintained throughout follow-up while the device was operational. At 18-20 months postimplant, the patients IPG failed. Battery failure was associated with an increase in headache frequency so that within four months he was back to baseline in terms of his monthly moderate to severe headache days. Following battery replacement, it took a further 6-8 months to regain the previous levels of benefit.

In the patient with coexistent chronic cluster headache and NDPH with migrainous features (patient 9) daily cluster attack frequency fell by more than $50 \%$ at final follow-up despite there being no response in their NDPH with migrainous features.

\begin{tabular}{|c|c|c|c|c|c|c|c|c|c|c|}
\hline & $\begin{array}{l}\text { Age } \\
\text { (years) }\end{array}$ & Sex & $\begin{array}{l}\text { Duration } \\
\text { (years) }\end{array}$ & Laterality & $\begin{array}{l}\text { Monthly } \\
\text { moderate-to-severe HA days }\end{array}$ & Mean daily VRS & $\begin{array}{l}\text { Medication } \\
\text { overuse }\end{array}$ & $\begin{array}{l}\text { Previous } \\
\text { preventatives }\end{array}$ & $\begin{array}{l}\text { Response } \\
\text { GONB }\end{array}$ & $\begin{array}{l}\text { Follow-up } \\
\text { (months) }\end{array}$ \\
\hline 1 & 33 & $\mathrm{~F}$ & 13 & Bilateral & 30 & 8 & No & 11 & Negative & 65 \\
\hline 2 & 62 & $M$ & 8 & Bilateral & 30 & 8 & No & 13 & Negative & 49 \\
\hline 3 & 29 & $F$ & 8 & Unilateral & 30 & 5 & Yes & 11 & Negative & 64 \\
\hline 4 & 37 & $M$ & 5 & Bilateral & 30 & 8 & No & 10 & Negative & 51 \\
\hline 5 & 46 & $M$ & 6 & Unilateral & 30 & 6 & No & 10 & Positive & 108 \\
\hline 6 & 42 & $M$ & 12 & Bilateral & 30 & 7 & No & 11 & Negative & 89 \\
\hline 7 & 64 & $F$ & 10 & Bilateral & 30 & 6 & No & 11 & Negative & 53 \\
\hline 8 & 34 & $\mathrm{~F}$ & 16 & Bilateral & 30 & 9 & No & 12 & Negative & 27 \\
\hline 9 & 49 & $\mathrm{M}$ & 3 & Unilateral & 30 & 7 & Yes* & 12 & Positive & 32 \\
\hline Median & 42 & $5 M: 4 F$ & 8 & 6 Bilateral: & 30 & 7.00 & $7 \mathrm{No}:$ & 11 & 7 Negative: & 53.00 \\
\hline Range & $29-64$ & & $3-16$ & 3 Unilateral & (0) & $5-9$ & 2 Yes & $10-13$ & 2 Positive & $27-108$ \\
\hline$(I Q R)$ & (22) & & (7) & & & $(2.00)$ & & $(3.00)$ & & $(36.50)$ \\
\hline
\end{tabular}


Table 2. Previous Medications Used for Treatment of NDPH Prior to ONS.

\begin{tabular}{|c|c|c|c|c|c|c|c|c|c|c|}
\hline & 1 & 2 & 3 & 4 & 5 & 6 & 7 & 8 & 9 & Median dose \\
\hline Propranolol & DNK & $80 \mathrm{mg}$ & $160 \mathrm{mg}$ & - & DNK & $80 \mathrm{mg}$ & $160 \mathrm{mg}$ & $80 \mathrm{mg}$ & $40 \mathrm{mg}$ & $100 \mathrm{mg}$ \\
\hline Topiramate & $50 \mathrm{mg}$ & - & $200 \mathrm{mg}$ & $400 \mathrm{mg}$ & $100 \mathrm{mg}$ & $100 \mathrm{mg}$ & $200 \mathrm{mg}$ & DNK & $25 \mathrm{mg}$ & $153.57 \mathrm{mg}$ \\
\hline Sodium valproate & $900 \mathrm{mg}$ & $2000 \mathrm{mg}$ & - & $3000 \mathrm{mg}$ & DNK & 100 mg & DNK & DNK & $200 \mathrm{mg}$ & 1040 mg \\
\hline Pizotifen & $2.5 \mathrm{mg}$ & $3 \mathrm{mg}$ & DNK & - & DNK & DNK & - & DNK & $1.5 \mathrm{mg}$ & $2.33 \mathrm{mg}$ \\
\hline Flunarizine & $10 \mathrm{mg}$ & - & $10 \mathrm{mg}$ & $10 \mathrm{mg}$ & $10 \mathrm{mg}$ & - & $10 \mathrm{mg}$ & $10 \mathrm{mg}$ & - & 10 mg \\
\hline Methysergide & $6 \mathrm{mg}$ & - & - & $12 \mathrm{mg}$ & $8 \mathrm{mg}$ & $1 \mathrm{mg}$ & DNK & - & $9 \mathrm{mg}$ & $7.2 \mathrm{mg}$ \\
\hline Gabapentin & $2700 \mathrm{mg}$ & $1800 \mathrm{mg}$ & $2700 \mathrm{mg}$ & - & $3600 \mathrm{mg}$ & DNK & DNK & $1600 \mathrm{mg}$ & $1800 \mathrm{mg}$ & $2366.66 \mathrm{mg}$ \\
\hline Pregabalin & - & 600 mg & - & $600 \mathrm{mg}$ & - & 300 mg & - & DNK & 400 mg & $475 \mathrm{mg}$ \\
\hline Tricyclic Anti-depressant & Yes & Yes & Yes & Yes & Yes & Yes & Yes & Yes & Yes & \\
\hline Amitriptyline & DNK & $10 \mathrm{mg}$ & $50 \mathrm{mg}$ & $200 \mathrm{mg}$ & DNK & $25 \mathrm{mg}$ & DNK & DNK & 100 mg & 77 mg \\
\hline Dosulepin & $75 \mathrm{mg}$ & $150 \mathrm{mg}$ & - & - & - & $75 \mathrm{mg}$ & $75 \mathrm{mg}$ & $75 \mathrm{mg}$ & - & $93.75 \mathrm{mg}$ \\
\hline \multirow[t]{5}{*}{ Other } & DHE & Botox & Botox & DHE & DHE & DHE & DHE & Botox & DHE & \\
\hline & GONB & DHE & $\mathrm{DHE}$ & Indomethacin & GONB & GONB & GONB & GONB & GONB & \\
\hline & & GONB & Indomethacin & GONB & & & Candesartan & Acupuncture & MCNB & \\
\hline & & MCNB & GONB & MCNB & & & & & Indomethacin & \\
\hline & & $\begin{array}{l}\text { Co-enzyme } \\
\text { Q10 }\end{array}$ & MCNB & & & & & & & \\
\hline
\end{tabular}

BOTOX, onabotulinum toxin A; DHE, dihydroergotamine; DNK, do not know; GONB, greater occipital nerve block; MCNB, multiple cranial nerve block.

Table 3. Headache Characteristics Before and After Treatment.

\begin{tabular}{|c|c|c|c|c|}
\hline $\begin{array}{l}\text { Follow-up } \\
\text { (months) }\end{array}$ & $\begin{array}{c}\text { Moderate-to-severe } \\
\text { headache days }\end{array}$ & Mean daily VRS & $\begin{array}{l}\text { Mean daily pain } \\
\text { duration (hours) }\end{array}$ & $\begin{array}{c}\text { Estimated } \\
\text { improvement }^{\dagger}\end{array}$ \\
\hline
\end{tabular}

\begin{tabular}{|c|c|c|c|c|c|c|c|c|c|c|c|}
\hline & & Pre-ONS & Post-ONS & $\%$ Change & Pre-ONS & Post-ONS & VRS change & Pre-ONS & Post-ONS & $\%$ Change & \\
\hline $1^{\S}$ & 65 & 30 & 30 & 0 & 8 & 8 & 0 & 16.00 & 16.00 & 0 & 0 \\
\hline 2 & 49 & 30 & 30 & 0 & 8 & 4 & 4 & 18.00 & 18.00 & 0 & 30 \\
\hline $3^{\S}$ & 64 & 30 & 30 & 0 & 5 & 5 & 0 & 15.00 & 16.00 & 0 & $\begin{array}{l}0 \text { (70\% prior to } \\
\text { battery failure) }\end{array}$ \\
\hline 4 & 51 & 30 & 30 & 0 & 8 & 7 & 1 & 16.00 & 16.00 & 0 & 0 \\
\hline $5^{\natural}$ & 108 & 30 & 8 & $73.3 \%$ & 6 & 1 & 5 & 17.00 & 17.00 & 0 & 90 \\
\hline 6 & 89 & 30 & 30 & 0 & 7 & 7 & 0 & 17.00 & 18.00 & 0 & 0 \\
\hline 7 & 53 & 30 & 29 & $3.3 \%$ & 6 & 7 & 0 & 20.00 & 20.00 & 0 & 5 \\
\hline 8 & 27 & 30 & 30 & 0 & 9 & 6 & 3 & 18.00 & 18.00 & 0 & 38 \\
\hline 9 & 32 & 30 & 30 & 0 & 7 & 6 & 1 & 18.00 & 18.00 & 0 & 50 \\
\hline Median & 53.00 & 30 & 30 & 0.0 & 7 & 6 & 1.00 & 17.00 & 18.00 & 0 & \\
\hline$(I Q R)$ & (36.5) & (0) & $(0.5)$ & $(0.5)$ & (2) & (2.5) & (3.50) & $(2.00)$ & $(2.00)$ & & \\
\hline
\end{tabular}

${ }^{*} p<0.05$.

†Patient estimate of improvement at final follow-up.

${ }^{\ddagger}$ Patient asked if they would recommend the procedure to another person with their disorder.

${ }^{\S}$ ONS nonfunctioning at time of follow-up, awaiting replacement battery.

"ONS removed at final follow-up.

IQR, interquartile range; ONS, occipital nerve stimulation; VRS, verbal rating scale.

\section{Medication Use}

Patient 2 and patient 7 were taking at least one preventative medication at the time of implantation. At final follow-up, patient 2 had stopped all oral medications but was receiving regular occipital nerve blocks. Although they stated they found these beneficial, they showed no change in the median moderate to severe headache days. Patient 7 had stopped their original oral medications by final follow-up (flunarizine and topiramate) but was taking candesartan with no positive effect. Two other patients (patient 4 and patient 9) had started preventative medications by final follow-up yet reported no change in median monthly to severe headache days.

At both time of implant and final follow-up, the median number of days patients used any type of acute medication was zero with no change $(p=0.144)$. As previously discussed, patient 3 had medication overuse prior to implant in the form of daily opiates. At final follow-up, this patient had stopped all opiates and was using paracetamol less than 15 days a month and so no longer met the criteria for medication overuse by ICHD-3 guidelines (2). Patient 9 with coexistent chronic cluster headache and NDPH 
Table 4. Headache Specific Disability, Affect, and Quality of Life Score Changes With ONS

\begin{tabular}{|c|c|c|c|c|}
\hline & Pre-ONS median (IQR) & Post-ONS median (IQR) & Median change (IQR) & $p$ value \\
\hline & Range & Range & Range & \\
\hline \multirow[t]{2}{*}{$\operatorname{MIDAS}(n=9)$} & $64.00(184.00)$ & $21.00(256.00)$ & $-5.00(66.5)$ & 0.674 \\
\hline & $8-270$ & $0-270$ & -90 to 105 & \\
\hline \multirow[t]{2}{*}{ HIT-6 $(n=9)$} & $66.00(6.50)$ & $65.00(6.50)$ & $0.0(7)$ & 0.446 \\
\hline & $36-70$ & $44-82$ & -46 to 17 & \\
\hline \multirow[t]{2}{*}{ HAD-A $(n=9)$} & $9.00(5.50)$ & $7.00(3.50)$ & $1.0(5.50)$ & 0.107 \\
\hline & $4-16$ & $2-9$ & -2 to 9 & \\
\hline \multirow[t]{2}{*}{ HAD-D $(n=9)$} & $8.00(4.50)$ & $7.00(4.50)$ & $2.00(5.50)$ & 0.176 \\
\hline & $2-14$ & $1-11$ & -1 to 8 & \\
\hline \multirow[t]{2}{*}{ BDI-II $(n=9)$} & $21.00(11.50)$ & $9.00(10.00)$ & $3.00(6.50)$ & $0.008^{*}$ \\
\hline & $6-28$ & $4-22$ & 1 to 21 & \\
\hline \multirow[t]{2}{*}{ SF-36 physical $(n=9)$} & $37.00(17.75)$ & $35.50(0.25)$ & $0.00(17.35)$ & 0.499 \\
\hline & $20.30-47.20$ & $20.30-56.20$ & -19.20 to 11.70 & \\
\hline \multirow[t]{2}{*}{ SF-36 mental $(n=9)$} & $41.70(21.25)$ & $49.80(8.2)$ & $-9.10(17.3)$ & 0.063 \\
\hline & $24.90-53.40$ & $31.20-61.20$ & -20.20 to 6.90 & \\
\hline \multirow[t]{2}{*}{ Euro-QoL $(n=7)$} & $0.76(0.12)$ & $0.79(0.12)$ & $0.00(0.02)$ & 0.715 \\
\hline & $0.71-0.83$ & $0.48-0.83$ & -0.07 to 0.28 & \\
\hline \multirow[t]{2}{*}{ Euro-Scale $(n=7)$} & $50.00(20.00)$ & $60.00(30.00)$ & $0.0(30.00)$ & 0.273 \\
\hline & $30-80$ & 20-95 & -35.00 to 10.00 & \\
\hline
\end{tabular}

BDI-II, Becks Depression Inventory; HAD-A, Hospital Anxiety and Depression scores-anxiety specific; HAD-D, Hospital Anxiety and Depression scoresdepression-specific; HIT-6, Headache Impact Test; IQR, interquartile range; MIDAS, Migraine Disability Assessment Scale; SF-36, Short Form 36.

with migraine features had reduced their triptans from twice daily to twice a week post-ONS implant.

\section{Stimulation Settings}

Mean stimulation amplitude was $1.46 \mathrm{~V}(0.29-3.95)$, pulse width 449.90 us (370-570), and frequency $72.13 \mathrm{~Hz}(50-140)$.

Throughout follow-up, six patients had their ONS turned off for a period. Two were due to lack of efficacy and eventual removal, three were due to battery failure, and one due to failure of the battery caused by the patient not charging the battery. In three of these patients, their headaches worsened when the ONS was off despite the fact that only one patient was reporting a positive effect prior to ONS switch off. The mean time to pain from ONS switch off to headache worsening was 9.00 months (6-48 months).

\section{Adverse Events}

A total of 15 adverse events were recorded in nine patients and 12 of these events required additional surgical input. One patient (patient 1) suffered an electrode erosion a month after implant which required surgical revision. One patient suffered an infection over a lead connector (patient 5) which resulted in the removal and subsequent reinsertion of the whole ONS system. One patient (patient 7) suffered from three repeated battery failures after only 5-6 months. This led to a revision and replacement of the ONS system with a rechargeable device. No episodes of lead migration or fracture were recorded.

\section{DISCUSSION}

Since the initial description of NDPH by Vanast a benign selflimiting headache with tension-type features the clinical view of the condition has changed somewhat (1). The original diagnostic criteria in the 2004 ICHD-2 is of a headache that within three days of onset is daily and unremitting for more than three months, which has at least two characteristics from: bilateral location, nonpulsatile nature, mild-moderate intensity, not aggravated by movement and which is not accompanied by nausea or vomiting and more than one of photophobia or phonophobia (15). The main differential is of chronic tension-type headache. However, since this time numerous case series have found that migraine features not described in the ICHD-2 classification are common. Robbins et al. found that $56.3 \%$ of their cohort of 71 patients with a headache persistent from onset failed to fulfill the ICHD-2 criteria because of their migrainous features (4). Peng et al. phenotyped 92 NDPH in their clinic of which 35.9\% reported features of migraine and a majority of the cohort of $\mathrm{Li}$ and Rozen described migraine associated symptoms such as nausea (68\%), photophobia (66\%), and phonophobia $(61 \%)(16,17)$. The increasing evidence of a wider clinical spectrum to NDPH has led to ICHD-3 including migraine features within the diagnostic criteria allowing a much larger number of patients to be included (2). The prognosis initially thought to be very positive also has been reassessed. In the original Vanast cohort, 73\% with NDPH had resolved without treatment within two years of onset (1). Now, it appears that patients with NDPH, especially those with migraine features, appear to have a poorer prognosis than chronic migraine and often prove medically refractory. The cohort of Robbins et al. found that $75.0 \%$ of those with NDPH with migraine features had a persistent and continuous headache from onset with a mean duration of 31 months compared to the $77.4 \%$ of those with ICDH-2 defined NDPH which had a mean duration of only 18 months (4). Across the cohort as a whole, $63.6 \%$ of those with remission did so within 24 months. In the group of Peng et al., after a mean follow-up of 50.1 months post-headache onset, only $26.4 \%$ were headache free despite $75 / 92$ patients being treated with preventative drugs (16). A cohort of 
30 Japanese patients with NDPH duration of 39.5 months before presentation were treated with various preventative medications (5). Only $27 \%$ of these patients reported a good response to treatment, $20 \%$ a minimal effect, and $50 \%$ reported no effect at all. This information suggests that those patients with NDPH who remit are likely to do so early and that those who do not are unlikely to respond to current treatments.

In terms of current treatments for NDPH, there have been no randomized trials to date. Most specialists will treat NDPH based on the clinical subtype of their headache-migraine or tensiontype. There has been some suggestion of specific NDPH treatments such as gabapentin, topiramate, doxycycline (on the basis of a possible infective etiology to NDPH), steroids, and mexiletine (18). None of these agents have shown promise in the clinical setting. Robbins et al. have reported the effects of multiple cranial nerve blocks (MCNBs) on NDPH stating that although 54\% had an acute response to the procedure the effect only lasted for 24 hours on average (4). Our units MCNB data showed that only $10 \%$ of patients reported a response to the procedure compared to $49 \%$ of chronic migraine patients (19).

ONS has been used to treat refractory chronic daily headaches in particular chronic migraine. There are three randomized controlled trials of ONS in chronic migraine and although results are somewhat contradictory, a meta-analysis of them suggests an overall positive response (7-11). The ONSTIM trial (ONS for the treatment of intractable chronic migraine headache) conducted in 2010 included 77 patients with chronic migraine (10). The threemonth responder rates (subjects reporting more than $50 \%$ reduction in monthly headache days or more than three points reduction in pain intensity) was 39\% for the treatment group, $6 \%$ for the sham-control group, and $0 \%$ for the conventual medical management group. The PRISM (Precision Implantable Stimulator for Migraine) study is still only available in abstract form despite publication in 2009 but it was a negative study reporting no difference in outcomes at three months between sham and active groups (9). The largest randomized controlled trial of ONS in migraine was conducted by Silberstein et al. and involved 157 patients with refractory chronic migraine (11). The primary outcome measure of a $50 \%$ or more reduction in average pain intensity after three months of treatment was negative; however, a number of secondary outcomes, including a $30 \%$ reduction in pain severity and headache frequency, did show a significant change, suggesting that ONS did have some positive benefit in chronic migraine. A long-term follow-up of this cohort showed that after 52 weeks there was a significant drop in monthly headache days of 6.7 days ( \pm 8.4 days) and that $47.8 \%$ of patients reported a more than $50 \%$ reduction in pain severity or headache days (8). A meta-analysis of the pooled results of the three studies show that three months of ONS treatment for chronic migraine is associated with a mean reduction of moderate to severe headache days of 2.59 days when compared to sham (7).

There are numerous case series of ONS for chronic migraine including our own units' cohort of 53 patients with medically refractory chronic migraine treated with the same ONS procedure (surgery and programming) as our current NDPH series $(12,20)$. For chronic migraine, our unit reported a clinical response $(30 \%$ reduction in moderate to severe headache days) in $45.3 \%$ of the group with a median follow-up of 42.00 months. Significant reductions also were seen in pain intensity and duration as well as in quality of life scores. These patients were treated in exactly the same way as the NDPH cohort, yet the outcome is strikingly different. Only one patient $(11.1 \%)$ showed a clinical response (same definition as for chronic migraine patients) and there was no improvement in the same secondary outcome measures such as quality of life or disability scores. This difference is further compounded by our chronic migraine group being highly refractory and complex having failed a much higher number of medications, having continuous background pains and a number of coexistent headache types.

The poor treatment response of NDPH with migraine features to ONS supports the notion that in those that do not spontaneously resolve early on in the course of the syndrome, their condition will prove highly resistant to treatments otherwise useful in chronic migraine. It also adds to the limited data that nonoral treatments such as nerve blocks appear to be of limited use in the condition. The reason for this emerging difference in treatment response of chronic migraine and NDPH with migraine features poses interesting questions over the underlying pathophysiology of NDPH. Such a dramatic difference in response to oral medications, nerve blocks and now ONS suggests that there may be a very different underlying etiology to chronic migraine and NDPH with migraine features despite the clinical similarities. NDPH as a secondary headache is a concept previously raised in the NDPH literature. Studies have looked at potential trigger events in NDPH such as infections, trauma, stress, and surgical procedures (21). Vanast et al. initially suggested a viral trigger, specifically Epstein Barr virus, which caused a prolonged autoimmune disorder manifesting as chronic headache (22). Rozen and Swidan also explored a possible inflammatory cause of NDPH reporting increased levels of pro-inflammatory cytokines (tumor necrosis factor) in the cerebrospinal fluid of subjects with the syndrome (23). However, findings have not been replicated and methodological issues have cast doubt on the conclusions of Rozen and Swidan's study (24). Other causes speculated to be relevant in NDPH include cervical hypermobility and even intracranial pressure disturbances $(25,26)$. If $\mathrm{NDPH}$ is a secondary headache, this may explain why ONS is so much less effective than in chronic migraine as the treatment is not targeting the cause of the secondary headache and therefore, the original driver to create pain is maintained despite attempts to wind down the central pain system.

The main limitation of this study is the small sample size; however, NDPH is a rare disorder with estimated prevalence between $0.03 \%$ and $0.1 \%$ of the population $(27,28)$, some of whom will respond to medical treatment or spontaneously improve. It is therefore unlikely that large series of patients with treatment refractory NDPH treated with ONS will be reported. This was an uncontrolled open label study with no comparison to placebo or sham-stimulation. Given the rarity of the condition, it is unlikely that a randomized controlled trial of ONS for NDPH will ever be conducted. The response rate of NDPH patients in our group of patients was below that seen in the sham stimulation group in randomized controlled trials of ONS for chronic migraine (11).

Our cohort suggests that ONS is not an effective treatment for NDPH with migraine features even when conducted in specialized and experienced units. If this finding is duplicated in other units, it may be that the treatment should not be offered to these patients due to the significant cost and risk:benefit ratio. The stark differences between response rates of chronic migraine and $\mathrm{NDPH}$ with migraine features highlights the potential of different underlying mechanisms of the two clinically similar conditions. There is a need for further studies into NDPH and its etiology and also into new distinctive treatment regimes. 


\section{Authorship Statement}

Susie Lagrata was responsible for the recruitment of subjects, analysis and interpretation of data, drafting and revision of manuscript. Sanjay Cheema was responsible for the manuscript revision. Laurence Watkins performed surgery and manuscript revision. Manjit Matharu was responsible for the study concept, recruitment of subjects, interpretation of data, and manuscript revision. All authors approved the final version of the manuscript.

\section{How to Cite this Article:}

Lagrata S., Cheema S., Watkins L., Matharu M. 2021. LongTerm Outcomes of Occipital Nerve Stimulation for New Daily Persistent Headache With Migrainous Features. Neuromodulation 2021; 24: 1093-1099

\section{REFERENCES}

1. Vanast WJ, Edmondton M. New daily persistent headaches definition of a benign syndrome. Program abstracts of the twenty-eighth Annual Meeting of the American Association for the Study of Headache June 27, 28 and 29, 1986, Chicago, Illinois U.S.A. Headache 1986;26:309-321.

2. Headache Classification Committee of the International Headache Society (IHS). The international classification of headache disorders, 3rd edition (beta version). Cephalalgia 2018;38:1-211.

3. Rozen TD. New daily persistent headache: an update. Curr Pain Headache Rep 2014;18:431.

4. Robbins MS, Grosberg BM, Napchan U, Crystal SC, Lipton RB. Clinical and prognostic subforms of new daily-persistent headache. Neurology 2010;74:1358-1364.

5. Takase Y, Nakano M, Tatsumi C, Matsuyama T. Clinical features, effectiveness of drug-based treatment, and prognosis of new daily persistent headache (NDPH): 30 cases in Japan. Cephalalgia 2004;24:955-959.

6. Prakash S, Saini S, Rana KR, Mahato P. Refining clinical features and therapeutic options of new daily persistent headache: a retrospective study of 63 patients in India. J Headache Pain 2012;13:477-485.

7. Chen YF, Bramley G, Unwin G et al. Occipital nerve stimulation for chronic migraine-a systematic review and meta-analysis. PLoS One 2015;10:e0116786.

8. Dodick DW, Silberstein SD, Reed KL et al. Safety and efficacy of peripheral nerve stimulation of the occipital nerves for the management of chronic migraine: long-term results from a randomized, multicenter, double-blinded, controlled study. Cephalalgia 2015;35:344-358.

9. Lipton R, Goadsby PJ, Cady R et al. PRISM study: occipital nerve stimulation for treatment-refractory migraine. Cephalalgia 2009;29:30.

10. Saper JR, Dodick DW, Silberstein SD, McCarville S, Sun M, Goadsby PJ. Occipita nerve stimulation for the treatment of intractable chronic migraine headache: ONSTIM feasibility study. Cephalalgia 2011;31:271-285.

11. Silberstein SD, Dodick DW, Saper J et al. Safety and efficacy of peripheral nerve stimulation of the occipital nerves for the management of chronic migraine: results from a randomized, multicenter, double-blinded, controlled study. Cephalalgia 2012:32:1165-1179.

12. Miller S, Watkins L, Matharu M. Long-term outcomes of occipital nerve stimulation for chronic migraine: a cohort of 53 patients. J Headache Pain 2016;17:68.

13. Goadsby PJ, Schoenen J, Ferrari MD, Silberstein SD, Dodick D. Towards a definition of intractable headache for use in clinical practice and trials. Cephalalgia 2006;26:1168-1170.

14. Silberstein S, Tfelt-Hansen P, Dodick DW et al. Guidelines for controlled trials of prophylactic treatment of chronic migraine in adults. Cephalalgia 2008;28: 484-495.

15. Headache Classification Subcommittee of the International Headache Society. The international classification of headache disorders, 2nd edition. Cephalalgia 2004;24:1-160.
16. Peng KP, Fuh JL, Yuan HK, Shia BC, Wang SJ. New daily persistent headache: should migrainous features be incorporated? Cephalalgia 2011;31:1561-1569.

17. Li D, Rozen TD. The clinical characteristics of new daily persistent headache. Cephalalgia 2002;22:66-69.

18. Rozen TD. New daily persistent headache: clinical perspective. Headache 2011 51:641-649.

19. Miller S, Lagrata S, Matharu M. Multiple cranial nerve blocks for the transitional treatment of chronic headaches. Cephalalgia 2019;39:1488-1499.

20. Magis D, Schoenen J. Advances and challenges in neurostimulation for headaches. Lancet Neurol 2012;11:708-719.

21. Rozen TD. Triggering events and new daily persistent headache: age and gender differences and insights on pathogenesis-a clinic-based study. Headache 2016; 56:164-173.

22. Vanast WJ, Diaz-Mitoma F, Tyrrell DL. Hypothesis: chronic benign daily headache is an immune disorder with a viral trigger. Headache 1987;27:138-142.

23. Rozen T, Swidan SZ. Elevation of CSF tumor necrosis factor alpha levels in new daily persistent headache and treatment refractory chronic migraine. Headache 2007;47:1050-1055.

24. Saxon A. CSF TNFalpha has not been shown to be elevated in headache patients. Headache 2015:55:1266.

25. Rozen TD, Roth JM, Denenberg N. Cervical spine joint hypermobility: a possible predisposing factor for new daily persistent headache. Cephalalgia 2006;26: $1182-1185$.

26. Goadsby PJ, Boes C. New daily persistent headache. J Neurol Neurosurg Psychiatry 2002;72:ii6-ii9.

27. Castillo J, Muñoz P, Guitera V, Pascual J. Kaplan Award 1998. Epidemiology of chronic daily headache in the general population. Headache 1999;39:190-196.

28. Grande RB, Aaseth K, Lundqvist C, Russell MB. Prevalence of new daily persistent headache in the general population. The Akershus study of chronic headache. Cephalalgia 2009;29:1149-1155.

\section{COMMENTS}

The use of occipital nerve stimulation in the treatment of new daily persistent headache (NDPH) is of major interest. This study showed that NDPH with migrainous features does not respond to occipital nerve stimulation compared to patients with chronic migraine who do.

Stephen Silberstein, MD Philadelphia, PA, USA

$* * *$

The response of even clear cut chronic migraine to occipital nerve stimulation (ONS) is very variable. By highlighting one headache subgroup with migrainous features for whom ONS is clearly not beneficial, the authors have provided very useful information to help with patient selection.

Interestingly, we have found that in patients with a history of chronic migraine that progresses from episodic migraine, the presence of headache absolutely every day predicts a poor response to ONS. Those who report at least some headache free days appear to do better. It may be that those with a headache every day have a different pathology, adverse psychological factors, or are simply well above the ceiling of the 'headache days' scale.

James Fitzgerald, MA, BM, BCh, PhD Oxford, UK 